ORIGINAL ARTICLE

\title{
Skin temperature recovery from cold provocation in workers exposed to vibration: a longitudinal study
}

\author{
M Cherniack, A Brammer, J Meyer, T Morse, D Peterson, R Fu
}

Occup Environ Med 2003;60:962-968

See end of article for authors' affiliations

....................

Correspondence to: Dr M Cherniack, Ergonomics Technology Center, University of Connecticut Health Center, 263 Farmington AvenueMC6210, Farmington, CT 06030-6210, USA; cherniack@nso.uchc.edu

Accepted 11 January 2003
Background: Vibration white finger (VWF) is characterised by arterial hyperresponsiveness and vasoconstriction following cold provocation. Several years after of removal from exposure, most subjects show improved finger systolic blood pressure (FSBP) under conditions of cold challenge, but continue to report cold hands and finger blanching.

Aims: To assess the underlying reasons for the persistence of cold symptoms.

Methods: A total of 204 former users of pneumatic tools with cold related hand symptoms were evaluated and then re-evaluated a year later. Symptoms were evaluated using the Stockholm Workshop Scale. Finger systolic blood pressure per cent (FSBP\%) was assessed by comparing digital blood pressure in a cold provoked and normalised state. Fingertip skin temperature was measured during cooling and occlusion and during rewarming and recovery.

Results: There were dramatic improvements in FSBP\% (14.3 $\mathrm{mm} \mathrm{Hg} \%)$, modest improvement in recovered skin temperature $\left(0.86^{\circ} \mathrm{C}\right)$, and no change in symptom stage. When the most symptomatic subjects $(n=75)$ were compared with the less symptomatic subjects $(n=129)$, there were similar inter-test improvements in FSBP\%. Skin temperature recovery improved in the less symptomatic $\left(+1.49^{\circ} \mathrm{C}\right)$, but did not change in the most symptomatic group $\left(-0.12^{\circ} \mathrm{C}\right)$. However, the more symptomatic group had higher temperatures at the initial test, thus qualifying the result.

Conclusions: Skin temperature recovery after cold challenge in subjects with VWF remains reduced in the symptomatic subjects several years after exposure removal. This is evident even when blood pressure has increased in the setting of cold provocation. Results suggest that in VWF, the dermal circulation remains impaired, even after the restoration of arterial blood pressure in the digits.
A bnormalities in digital circulation, characterised by cold white fingers, have been a recognised hallmark of vibration induced vascular injury for more than 80 years. The clinical condition, cold induced vibration white fingers (VWF), also known as "occupational Raynaud's phenomenon", includes components of exaggerated vasoconstriction and impaired vasodilatation. Cold provocation testing of the fingers and hands simulates the interruption of digital blood flow that is presumed to occur in cold environments. The two general approaches to cold provocation testing are blood pressure and skin temperature measurements, the latter a presumed surrogate for blood flow. For more than 20 years, the combination of digital occlusion with local cold provocation, using a water inflatable inlet cuff, and measurement of finger blood pressure or blood flow by strain gauge or sensor, has been standardised and used extensively in fieldwork. ${ }^{12}$ A second less standardised approach involves measurement of finger skin temperature (FST) following cold provocation. ${ }^{34}$

In a previous report on more than 200 vibration exposed and symptomatic subjects, who were tested and subsequently retested, we observed that: (1) finger systolic blood pressure (FSBP), assessed by cold provocation, improved following termination of vibratory exposure; (2) recovery was retarded in smokers (reversed by cessation); and (3) symptoms persisted despite improved FSBP\%. ${ }^{5}$ Other investigators ${ }^{67}$ had noted the temporal discrepancy between improvement in FSBP and lack of symptom reduction following exposure reduction; one author concluding that symptomatic VWF is non-remediable. ${ }^{8}$

The aim of this study was to further explore and to examine reasons for persistent cold provoked symptoms when objective test parameters improved. A different aspect of the cold response-the stability and recovery of finger skin temperature after a cold challenge-was examined. The presumption was that reduced digital skin temperatures, under ambient or cold conditions, might predict a pattern of symptomatic hyperresponsiveness to cold. The hypothesis is that the historical description of cold digits with normal arterial blood pressure may reflect measurably cold skin, possibly due to deficiencies within the superficial nutritive capillaries.

\section{METHODS \\ Subjects}

Two hundred and four subjects, referred to a university medical centre for VWF evaluation 1988-94, were studied. All were current, or former, skilled shipyard metalworkers from trades with documented pneumatic tool use that averaged $>10$ hours per week. Vascular assessment included grading of clinical symptoms using the Stockholm Workshop Scale," completion of a supplemental symptoms questionnaire, and a cold provocation test. The Stockholm Workshop Scale is a consensus rating system, developed by a hand-arm vibration expert committee for international standardisation. It classifies VWF into progressive symptom categories that range from 0 to IV. ${ }^{9}$ Since stage 0 indicates absence of symptoms, and stage IV represents trophic changes, which were not reported in this group, essentially all subjects fell into stages I-III. Stage III consists of frequent attacks of finger blanching

\footnotetext{
Abbreviations: FSBP, finger systolic blood pressure; FST, finger skin temperature; FTI, finger temperature index; HAVS, hand-arm vibration syndrome; RWI, rewarming index; VWF, vibration white finger
} 
Main messages

- Following termination of exposure to hand-arm vibration, cold challenge testing on symptomatic workers shows progressive improvement in finger systolic blood pressure (FSBP), slight improvement in finger temperature recovery, and little or no change in symptom status.

- Finger skin temperature (FST) and symptom staging are poorly associated.

- The pathology and recovery pattern in vibration white fingers (VWF) is complex and may involve separate lesions to the dermal capillary and deeper arterial circulations.

that involve most fingers, and extends over the full finger length. Stage I consists of more occasional blanching attacks confined to the fingertips of one of more fingers. Stage II defines an intermediate blanching pattern. The differentiation between Stage I and stage II is potentially ambiguous.

Individual subject files consisted of current and past occupational history, a symptom severity questionnaire, a description of pneumatic tool use, and detailed smoking histories. Current smoking history was also obtained at the time of the test.

\section{Finger systolic blood pressure (FSBP) experimental test}

The cold provocation test has been described earlier, ${ }^{5}$ and follows the technique proposed by Nielsen and Lassen. ${ }^{10}$ Subjects were instructed to refrain from drinking caffeinated beverages and from smoking on the day of the test. Subjects were tested in a supine position following a 30 minute acclimatisation period at ambient temperature of $21^{\circ} \mathrm{C}-24^{\circ} \mathrm{C}$. Hands were warmed to produce a pre-test digital skin temperature of $\geqslant 28^{\circ} \mathrm{C}$. Water was circulated at $15^{\circ} \mathrm{C}$, and then $10^{\circ} \mathrm{C}$, through a dual inlet digit occlusion cuff. In baseline and rewarming sequences, water was circulated at $30^{\circ} \mathrm{C}$. FSBP was simultaneously measured in a test and noncooled reference finger (the thumb unless contraindicated by disease). Finger cooling was augmented by the use of a truncal cooling blanket. Results are presented as a proportion (test finger/reference finger) - then normalised to the ambient temperature, $30^{\circ} \mathrm{C}$ as finger systolic blood pressure per cent (FSBP\%). All FSBP repeated measurements employed the same method and apparatus as in the original test (Digimatic 2000, Medimatic, Copenhagen).

For each subject, there were five separate test runs: $30^{\circ} \mathrm{C}$ digital cooling (test 1 ), $30^{\circ} \mathrm{C}$ with body cooling (test 2 ), $15^{\circ} \mathrm{C}$ with body cooling (test 3 ), $10^{\circ} \mathrm{C}$ with body cooling (test 4 ), and rewarming at $30^{\circ} \mathrm{C}$ (test 5 ). All FSBP\% measurements presented in the tables compare test 4 to test 1 .

FSBP\% results are not normally distributed. One reason involves a possible artefact of measurement; the other is based in the probable pathophysiology of VWF. The measurement artefact reflects uncertainties in delineating FSBP measurements $<32 \mathrm{~mm} \mathrm{Hg}$, because venous pressures can mask low pressure arterial flow. In addition, most investigators have observed two peaks in the distribution of measured FSBP\%. Test results are either clustered at $\mathrm{FSBP}=0$, or are otherwise normally distributed. For these reasons, FSBP measurement results in this study are presented both as continuous and as grouped data. A leading contributor has argued that there are only two true categories of response: normal and FSBP $=0 .{ }^{1}$ The FSBP\% cut-off of 30
Policy implications

- Cold challenge testing in WWF produces results that should be interpreted with caution.

for the most abnormal results reflects the uncertainty of low arterial pressure measurement.

Finger skin temperature (FST) was recorded, using calibrated skin sensors, before, during, and after each occlusion cycle at the chest wall, test arm (antecubital fossa), and test finger. Finger temperature recovery was monitored at the end of the rewarming cycle and for the next 10 minutes under ambient conditions with the subject continuing to lie supine. The 10 minute interval has been recommended as optimal for temperature recovery tests. ${ }^{11}$

\section{Skin temperature indices}

The temperature indices (FTI, RWI 1, RWI 2) stand for finger temperature index and rewarming index 1 and 2, respectively. They were intended to relativise all values to a baseline. Table 1 lists the calculations for the skin temperature indices and the finger systolic blood pressure per cent. The FTI is a measure of the baseline to recovery residual, adjusted for arm temperature, and the rewarming indices describe a relation between maximum cooling and recovery fingertip temperatures. The FTI was constructed on the assumption that a comparison of the cold challenged digital temperature to an uncooled baseline-corrected for a "systemic change" in the arm temperature during testingmight be more meaningful than a simple skin temperature comparison. Similarly, the rewarming indices are the residuals and ratios of digit temperature, when the most cooled and recovery states are compared.

\section{Follow up criteria}

All 204 subjects had follow up studies performed one year after their initial study. Retesting was not mandatory; hence this was a highly selected retest cohort. The criteria for retesting were prior test abnormality on cold challenge plethsymography $(\mathrm{FSBP} \%<70)$, or significant unabated symptom (Stockholm Scale stage III) with normal plethysmography. No subjects were included who had continuous exposure to vibratory tools after the date of their initial test. For some subjects, skin temperature monitoring data were incomplete in 1988, having been conducted prior to finalisation of the temperature monitoring protocol or because of equipment limitations. Because of the centrality of skin

Table 1 Key indices used to report results for cold challenge testing

\begin{tabular}{|c|c|}
\hline Variable description & Definition \\
\hline $\begin{array}{l}\text { Finger systolic blood } \\
\text { pressure \% (FSBP\%) }\end{array}$ & $\begin{array}{l}\% \text { pressure }=100[(\mathrm{Pc} 30 \times \mathrm{Pt}) /(\mathrm{P} 30 \times \mathrm{Pct})] \\
\text { where } \mathrm{Pc} 30=\mathrm{FSBP} \text { of reference finger } \\
\text { at } 30^{\circ} \mathrm{C} ; \mathrm{Pct}=\text { systolic pressure of the } \\
\text { reference finger at cooling temperature } \\
(\mathrm{t}) ; \mathrm{P} 30 \text { and } \mathrm{Pt}=\text { respective values of the } \\
\text { cooled finger }\end{array}$ \\
\hline Finger temperature index (FTI) & $\mathrm{FTI}=\mathrm{TFT}-(\mathrm{T} 5 \mathrm{FT} 5 \times[\mathrm{T} 1 \mathrm{AT} 1 / \mathrm{T} 5 \mathrm{AT} 1])$ \\
\hline Rewarming index 1 (RWI 1) & RWI $1=$ T4TFT3 - T5TFT3 \\
\hline Rewarming index 2 (RWI 2) & RWI 2 = T5TFT3/T4TFT3 \\
\hline \multicolumn{2}{|c|}{$\begin{array}{l}\text { TFT, baseline finger temp }\left({ }^{\circ} \mathrm{C}\right) \text {. } \\
\text { T5TFT5, finger temp }\left({ }^{\circ} \mathrm{C}\right) \text { at } 10 \text { min recovery after rewarming. } \\
\text { T1AT1, baseline arm temp }\left({ }^{\circ} \mathrm{C}\right) \text {. } \\
\text { T5AT1, arm temp }\left({ }^{\circ} \mathrm{C}\right) \text { during rewarming. } \\
\text { T4TFT3, finger temp }\left({ }^{\circ} \mathrm{C}\right) \text { after } 10^{\circ} \mathrm{C} \text { cooling. } \\
\text { T5TFT3, finger temp }\left({ }^{\circ} \mathrm{C}\right) \text { after rewarming. }\end{array}$} \\
\hline
\end{tabular}


Table 2 Characteristics of all subjects comparing initial and follow up tests

\begin{tabular}{|c|c|c|c|c|c|}
\hline Variable name & Sample size & Initial test $(95 \% \mathrm{Cl})$ & Follow up test $(95 \% \mathrm{Cl})$ & Test difference $(95 \% \mathrm{Cl})$ & $p$ value \\
\hline$\%$ smokers & 204 & 61.76 & 34.80 & 26.96 & $<0.0001$ \\
\hline$\%$ subjects with $\mathrm{FSBP} \%=0$ & 204 & 35.78 & 20.59 & -15.19 & $<0.0001$ \\
\hline FSBP\% & 204 & $49.99 \pm 5.39$ & $63.40 \pm 4.82$ & $14.32 \pm 4.96$ & $<0.001$ \\
\hline FSBP $\% \geqslant 30^{*}$ & 120 & $77.38+3.27$ & $82.20+2.41$ & $-4.82+3.63$ & 0.01 \\
\hline Baseline arm temp ( $\left.{ }^{\circ} \mathrm{C}\right)$ & 202 & $32.20+0.20$ & $32.10+0.20$ & $-0.10+0.25$ & 0.42 \\
\hline Baseline finger temp $\left({ }^{\circ} \mathrm{C}\right)$ & 201 & $29.43 \pm 0.39$ & $30.12 \pm 0.41$ & $0.69 \pm 0.49$ & $<0.01$ \\
\hline Finger temp $\left({ }^{\circ} \mathrm{C}\right)$ at $10^{\circ} \mathrm{C}$ Cooling & 202 & $24.65 \pm 0.45$ & $25.57 \pm 0.49$ & $0.92 \pm 0.55$ & $<0.01$ \\
\hline Finger temp $\left({ }^{\circ} \mathrm{C}\right)$ at $30^{\circ} \mathrm{C}$ rewarmed & 201 & $24.64 \pm 0.47$ & $25.23 \pm 0.51$ & $0.58 \pm 0.59$ & 0.05 \\
\hline Finger temp ${ }^{\circ} \mathrm{C}$ at 10 min recovery & 177 & $27.12+0.59$ & $27.99+0.61$ & $0.86+0.65$ & 0.01 \\
\hline Finger temperature index (FTI) & 177 & $0.92 \pm 0.47$ & $0.44 \pm 0.45$ & $-0.47 \pm 0.57$ & 0.10 \\
\hline Rewarming index 1 & 201 & $-0.01 \pm 0.20$ & $0.33 \pm 0.18$ & $0.34 \pm 0.25$ & 0.01 \\
\hline Rewarming index 2 & 201 & $1.00 \pm 0.01$ & $0.99 \pm 0.01$ & $-0.014 \pm 0.01$ & 0.01 \\
\hline
\end{tabular}

temperature to this analysis, these subjects were dropped entirely, except where there were at least two subsequent tests with complete skin temperature data. In those cases the second test became the baseline test and the subsequent test became the "follow up" test. Accordingly, the nomenclature of "initial" and "follow up test" does not always designate a minimum of two tests. In subjects where there were more than two completed tests, the first and last test was used. For all retested subjects, FSBP\% was measured in the finger that was tested in the previous examination.

\section{Analysis}

Data were analysed using the SAS statistical software package. Continuous data were summarised as means and standard deviations. Differences between group means were tested using one or two way analyses of variance and multiple comparison tests. Inter-year comparisons were made using McNemar's test for grouped data and matched $t$ tests for continuous data. Non-parametric tests were used for small data sets $(n<15)$. The relation between variables expressed as means was evaluated by linear regression. The difference between categorical data tabulated in $2 \times k$ contingency tables was tested by the $\chi^{2}$ test. A p value of 0.05 was chosen as the limit of statistical significance.

\section{RESULTS}

Table 2 compares key results for all 204 subjects for the initial and follow up tests. The average age of the cohort at follow up was 43.9 years (range $25-70$ ). There was a dramatic intertest decline in reported smoking from $61.8 \%$ to $34.8 \%$. FSBP\% increased from $50.0 \%$ to $63.4 \%$ between the initial and follow up tests. Improvement is attributable to a decrease in subjects with FSBP\% <30, from $73(35.8 \%)$ to $42(20.6 \%)$. FSBP\% increases at follow up for subjects with initial FSBP\% $\geqslant 30$ were modest, less than 5\%. However, the mean initial test results were already in the low normal range, so improvements represent increased movement towards a population mean. Increases in the various temperature measurements were modest, never exceeding $1{ }^{\circ} \mathrm{C}$. Under all major test conditions-baseline, digital cooling, digital rewarmingdigital skin temperatures were warmer at the follow up test than at the initial test. Variances were narrow; accordingly temperature increases for digital skin were significant even where absolute increases were small. The various temperature indices did not offer significant refinement over unmodified temperatures. In the case of the rewarming indices that compared rewarmed digital skin temperature with digital temperature at maximum cooling, the results were significant, but they offered no advantage over the simple recovery temperature measured 10 minutes after rewarming; consequently they are dropped from later analyses. The FTI appeared to show relatively large proportional differences between tests, although the adjusted group deviation from baseline was $<1{ }^{\circ} \mathrm{C}$. The variances were too large to afford meaningful comparison.

Table 3 presents comparative changes in Stockholm Workshop symptom stage between the initial and the follow up tests. There was only modest variation in symptom stage between tests, with 163 of 204 subjects (79.9\%) remaining at their original stage when retested. Among the subjects who reported a stage change, $25(12.3 \%)$ had deteriorated to a more symptomatic stage and $16(7.8 \%)$ had improved to a less symptomatic stage. At the time of the initial test, there were 63 subjects with Stockholm Workshop Scale stage III symptoms. The number of subjects at stage III increased to 75 at the time of the follow up test. There were 129 subjects rated at Stockholm Workshop Scale stage I or II (herein, stage I-II) at follow up.

Table 4 presents 15 subjects with symptomatic improvement. Multiple regressions of changes in FSBP\% and finger temperature were run on the full cohort, adjusted for initial levels and changes in clinical status. Changes in clinical status were not significant. Improvement in mean FSBP\% from $47.0 \%$ to $67.8 \%$ in the improved subjects was principally due to a decrease in the proportion of subjects with FSBP\% $<30$ from $40 \%$ to $20 \%$, figures almost identical to the larger

Table 3 Stockholm Workshop Scale stage change between initial and follow up test

\begin{tabular}{lllcc}
\hline Initial test stage & Follow up test stage & Direction & Cases & \% of cohort \\
\hline III & III & $\Leftrightarrow$ & 56 & 27 \\
II & II & $\Leftrightarrow$ & 60 & 29 \\
I & I & $\Leftrightarrow$ & 47 & 23 \\
I & II, III & $\Downarrow$ & 10 & 5 \\
II & III & $\Downarrow$ & 15 & 7 \\
III & II, I, O & $\Uparrow$ & 7 & 3 \\
II & I, O & $\Uparrow$ & 8 & 4 \\
O, I & 0 & $\Uparrow$ & 1 & 1 \\
& & & 204 & 100 \\
\hline
\end{tabular}

Key: $\Leftrightarrow$ no stage change; $\Downarrow$ stage deterioration; $\Uparrow$ stage amelioration. 
Table 4 Characteristics of 15 subjects reporting clinical improvement, comparing initial and follow up tests

\begin{tabular}{|c|c|c|c|c|c|}
\hline Variable description & Sample size & Initial test \pm SE & Follow up test \pm SE & Test difference \pm SE & $p$ value \\
\hline$\%$ smokers & 15 & 26.67 & 46.67 & $20 \%$ & 0.38 \\
\hline$\%$ subjects with FSBP $\%=0$ & 15 & $6(40 \%)$ & $3(20 \%)$ & $-20 \%$ & 0.38 \\
\hline FSBP\% & 15 & $47.04 \pm 11.03$ & $67.75 \pm 9.93$ & $20.71 \pm 10.91$ & 0.18 \\
\hline $\mathrm{FSBP} \% \geqslant 30^{*}$ & 8 & $83.10 \pm 5.73$ & $87.28 \pm 7.51$ & $4.18 \pm 8.63$ & 0.73 \\
\hline Baseline arm temp $\left({ }^{\circ} \mathrm{C}\right)$ & 15 & $32.09 \pm 0.32$ & $31.75 \pm 0.34$ & $-0.34 \pm 0.43$ & 1.00 \\
\hline Baseline finger temp $\left({ }^{\circ} \mathrm{C}\right)$ & 15 & $29.00 \pm 0.95$ & $29.60 \pm 0.86$ & $0.60 \pm 1.22$ & 1.00 \\
\hline Finger temp $\left({ }^{\circ} \mathrm{C}\right)$ at $10^{\circ} \mathrm{C}$ cooling & 15 & $25.33 \pm 1.15$ & $25.51 \pm 0.93$ & $0.18 \pm 1.02$ & 1.00 \\
\hline Finger temp $\left({ }^{\circ} \mathrm{C}\right)$ at $30^{\circ} \mathrm{C}$ rewarmed & 15 & $25.95 \pm 1.12$ & $25.33 \pm 0.90$ & $-0.6 \overline{2} \pm 1.11$ & 0.58 \\
\hline Finger temp $\left({ }^{\circ} \mathrm{C}\right)$ at $10 \mathrm{~min}$ recovery & 11 & $27.42 \pm 1.57$ & $27.13 \pm 1.28$ & $-0.29 \pm 1.13$ & 0.55 \\
\hline Finger temperature index (FTI) & 11 & $-0.23 \pm 0.78$ & $0.21 \pm 0.83$ & $0.44 \pm 0.68$ & 1.00 \\
\hline Rewarming index 1 & 15 & $-0.62 \pm 0.41$ & $0.19 \pm 0.36$ & $0.81 \pm 0.53$ & 0.12 \\
\hline Rewarming index 2 & 15 & $1.03 \pm 0.018$ & $1.00 \pm 0.02$ & $-0.03 \pm 0.02$ & 0.12 \\
\hline
\end{tabular}

cohort. There was no statistically significant movement towards warmer skin temperatures in the symptomatically improved group after follow up cold challenge. The test finger temperature at $10^{\circ} \mathrm{C}$ cooling was on average $0.18^{\circ} \mathrm{C}$ warmer, but the temperatures after rewarming and after an additional 10 minutes of recovery were 0.62 and $0.29^{\circ} \mathrm{C}$ cooler. An absence of inter-test improvement distinguishes this group from the larger cohort, but skin temperatures at the initial test were similar to those recorded at follow up in the larger cohort, meaning the larger cohort was cooler at initial testing. The small sample size limits inference and the implication of these modest differences is unclear.

Table 5 compares subjects with stage III symptoms at follow up testing with stage I-II subjects. The purpose of this comparison was to assess any relation between the most severe symptoms and skin temperature change. In most respects, the groups were similar. Both age and years of exposure to vibratory tools did not differ between the two groups. The interval between last exposure and the follow up test was actually longer for the more symptomatic (stage III) subjects by a factor of 9.2 months (35.68 versus 26.51 months), although the interval between the initial and follow up tests was virtually identical (12 versus 11 months). Current (but not former) smoking had been a significant predictor of delayed recovery of FSBP\% in our earlier study, but smoking rates were virtually identical in the two groups. There were more stage III subjects at follow up with an FSBP\% $<30$ (25.3\% versus $17.8 \%$ for stages I-II), but the proportional grouped differences between stage III and stage I-II subjects were not significant. The mean FSBP\% differences between the two groups and at initial and follow up tests are interesting. Despite the modest changes in symptom stage between tests, there were dramatic overall improvements in the FSBP\%. While the FSBP\% at the follow up test was somewhat lower for the stage III subjects compared with stage I-II subjects (59.2\% versus $65.9 \%)$, the interval improvement between the tests was actually somewhat greater ( 15.3 versus $13.8 \%$ ) for stage III subjects. None of these differences were statistically significant.

The variations in finger skin temperature present a somewhat different picture. For both symptom stage groups there is an overall similarity in skin temperature measurements under conditions of cold challenge, and there is a mild relative improvement during the follow up test compared with the initial measurement. The two groups diverge, when the inter-test patterns of skin temperature recovery are compared. Stage I-II subjects improved on average by $1.49^{\circ} \mathrm{C}$, whereas stage III subjects remained static, actually falling by $0.12^{\circ} \mathrm{C}$ when compared with the initial test. These group differences were not reflected in either baseline arm temperatures or test finger temperatures. This was the only inter-test parameter involving either $\mathrm{FSBP} \%$ or skin temperature that significantly differed between the two groups. It is also notable that the stage III subjects were actually warmer at baseline initially and had a relatively larger intertest increase in baseline digital skin temperature $-0.90^{\circ} \mathrm{C}$ compared with $0.56^{\circ} \mathrm{C}$ in the comparison group. The relative inter-test improvement in all of the cold provocation related

Table 5 Comparative characteristics of symptom stage III subjects with all other subjects at the second test

\begin{tabular}{|c|c|c|c|}
\hline & Stage III $(n=75)$ & Other stages $(n=129)$ & \\
\hline Variable description & $95 \% \mathrm{Cl}$ of mean & $95 \% \mathrm{Cl}$ of mean & p value \\
\hline Age at follow up test & $44.74 \pm 2.65$ & $43.49 \pm 2.04$ & 0.47 \\
\hline Interval (mth) between last exposure and follow up test & $35.68 \pm 8.53$ & $26.41 \pm 4.86$ & 0.04 \\
\hline Interval (mth) between last exposure and initial test & $23.20 \pm 6.39$ & $15.52 \pm 1.78$ & 0.04 \\
\hline Years exposed on job & $16.43 \pm 1.96$ & $15.50 \pm 1.76$ & 0.51 \\
\hline$\%$ smokers at follow up test & $26(34.67 \%)$ & $45(34.88 \%)$ & \\
\hline $\mathrm{FSBP} \%=0$ at follow up test & $19(25.3 \%)$ & $23(17.8 \%)$ & \\
\hline FSBP\% at follow up test & $59.16 \pm 8.53$ & $65.87 \pm 5.76$ & 0.18 \\
\hline FSBP\% at initial test & $43.87 \pm 8.82$ & $52.12 \pm 6.80$ & 0.16 \\
\hline FSBP\% $\Delta$ between tests & $15.28 \pm 8.11$ & $13.75 \pm 6.27$ & 0.82 \\
\hline Baseline arm temp $\left({ }^{\circ} \mathrm{C}\right)$ at follow up test & $32.10 \pm 0.33$ & $32.11 \pm 0.24$ & 0.96 \\
\hline Baseline finger temp $\left({ }^{\circ} \mathrm{C}\right)$ at follow up test & $30.48 \pm 0.59$ & $29.92 \pm 0.55$ & 0.19 \\
\hline Baseline finger temp $\left({ }^{\circ} \mathrm{C}\right) \Delta$ between tests & $0.90 \pm 0.69$ & $0.56 \pm 0.67$ & 0.88 \\
\hline Finger temp $\left({ }^{\circ} \mathrm{C}\right)$ at follow up test @ $10^{\circ} \mathrm{C}$ cooling & $25.57 \pm 0.82$ & $25.58 \pm 0.61$ & 0.93 \\
\hline Finger temp ( $\left.{ }^{\circ} \mathrm{C}\right) @ 10^{\circ} \mathrm{C}$ cooling $\Delta$ between tests & $0.72 \pm 1.12$ & $1.16 \pm 0.67$ & 0.14 \\
\hline Finger temp $\left({ }^{\circ} \mathrm{C}\right)$ at follow up test @ $30^{\circ} \mathrm{C}$ rewarm & $25.53 \pm 0.88$ & $25.09 \pm 0.61$ & 0.45 \\
\hline Finger temp ( $\left.{ }^{\circ} \mathrm{C}\right) @ 30^{\circ} \mathrm{C}$ rewarm $\Delta$ between tests & $0.46 \pm 1.02$ & $0.79 \pm 0.73$ & 0.52 \\
\hline Finger temp $\left({ }^{\circ} \mathrm{C}\right)$ at follow up test @ 10 min recovery & $27.84 \pm 0.92$ & $28.16 \pm 0.71$ & 0.36 \\
\hline Finger temp ${ }^{\circ} \mathrm{C} @ 10$ min recovery $\Delta$ between tests & $-0.12 \pm 1.06$ & $1.49 \pm 0.73$ & 0.03 \\
\hline
\end{tabular}


measures-cooling, rewarming, post-rewarming-tended to be lower in stage III compared with stage I-II subjects. The overall pattern is not straightforward.

Figure 1 presents a fuller representation of the pattern of test finger skin temperature variation during the course of testing. All temperature measurements were taken after release of the occlusion cuff for the five trials described above (plus an uncuffed baseline), then at 5 minutes and 10 minutes after rewarming. Finger skin temperatures are essentially identical for the stage III and stage I-II subjects through the cooling sequences at follow up testing. In fact, only skin temperatures for stage I-II subjects at the initial test vary from the overall pattern, being lower. Stage III subjects at the initial and follow up tests had a lower FSBP\% than stage I-II subjects. However, skin temperatures were actually lower for the latter group of subjects at the initial test and were identical to stage III subjects at the follow up test. In short, cooled and subsequent recovery temperatures were essentially similar for stage III subjects at the initial and follow up tests, and the large inter-test improvement for less symptomatic stage I-II subjects reflects lower skin temperatures at the initial test.

In a fuller regression model (table 6), rewarmed final temperature at the second test was regressed on age, latency from last exposure, years worked, smoking status, initial and follow up baseline digit temperatures and FSBP\% measurements, and symptom status. Initial and follow up test finger baseline temperatures and initial test rewarmed final temperatures had significant associations. FSBP\% was more loosely associated with rewarmed finger skin temperature; the symptom stage was not. For whatever value FST maintains as a predictor of long term symptom persistence, it is a poor cross sectional indicator of symptom stage in these workers.

\section{DISCUSSION}

The relation between FSBP\%, symptom stage, and baseline skin temperature, and temperature recovery is complex. The juxtaposition of an improvement in digital arterial blood

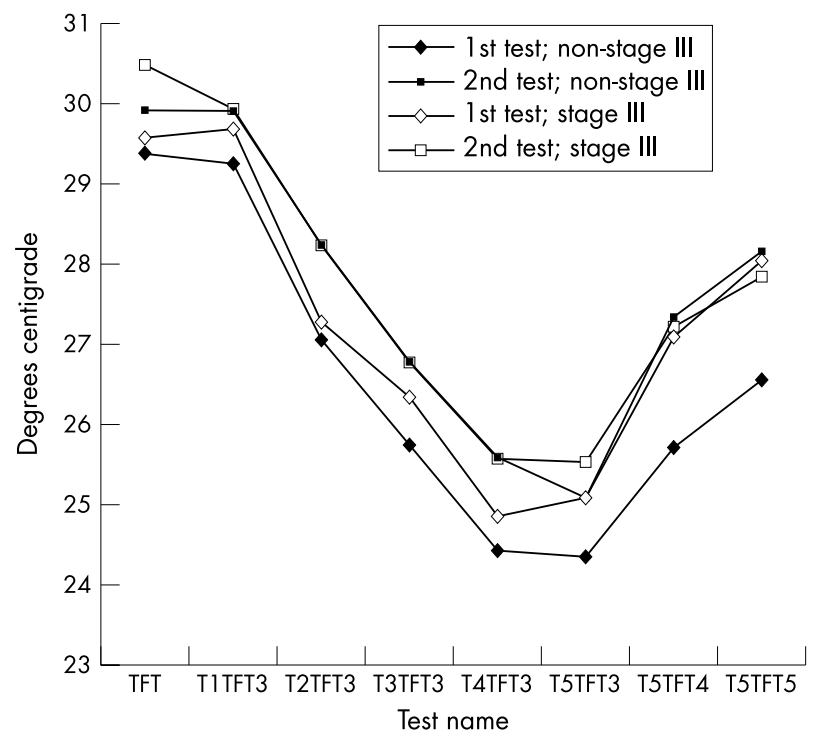

Figure 1 Comparison of fingertip temperatures for first and second tests. TFT, initial test finger temperature ( $\left.{ }^{\circ} \mathrm{C}\right)$. TIFT3, test finger temperature at $30^{\circ} \mathrm{C} ; \mathrm{T} 2 \mathrm{FT} 3$, test finger temperature at $30^{\circ} \mathrm{C}$, whole body cooling; T3FT3, test finger temperature cooled at $15^{\circ} \mathrm{C}$, whole body cooling; T4FT3, test finger temperature cooled at $10^{\circ} \mathrm{C}$, whole body cooling; $\mathrm{T} 5 \mathrm{FT} 3$, test finger temperature rewarmed at $30^{\circ} \mathrm{C}$; $\mathrm{T} 5 \mathrm{FT} 4$, test finger temperature at 5 minutes post rewarming; T5FT5, test finger temperature at 10 minutes post rewarming. pressure against relative absence of skin temperature improvement is consistent with the observation that finger systolic blood pressure tests may record interruption of digital blood flow in a context of vasoconstriction, whereas skin temperature recovery tests are measures of vasodilatation. ${ }^{12}$ By implication, while digital perfusion from arterial blood pressure and maintenance of skin temperature are associated, vibration may affect each system independently. The inability to improve skin rewarming among individuals with the most symptomatic cold hands seems to be characteristic of this population.

Several reservations specific to these particular tests require consideration. This was a hybrid test that combined elements of blood flow interruption with a cold stress. There may be advantages in the simultaneous administration of cold and mechanical stimuli. Since both FSBP and FST are outcomes of interest, cuff inflation and deflation, cooling and warming, and the induction of ischaemic intervals may create a test environment that is more representative of cold provocation under working conditions. However, skin temperature assessment is potentially contaminated and mechanical stresses cannot be isolated from temperature stresses. A second reservation applies to overly drawn inferences from temperature data featuring multiple outcome variables and small differences. The initial test results for stage III subjects (lower FSBP\%, greater symptoms, and higher recovery temperature compared to stage I-II) presents an ambiguous picture. If skin temperature recovery following cold challenge was a univariate predictor of symptomatically cold hands, the most symptomatic subjects at the initial test should have had the slowest degree of skin temperature recovery after rewarming. They did not. The differential relative improvement in stage I-II participants on follow up might suggest that more moderate symptoms were related to better skin perfusion. However, this only applies in relative terms. In absolute terms, stage I-II subjects were nondifferentiable from stage III subjects at follow up. Follow up was brief, however, and one year in the disease course of VWF, and improvements in FSBP might be mirrored later by skin temperature increase.

There was no unexposed control population, but published reference values also indicate a delay in recovery temperature in VWF patients. Lindsell and Griffin ${ }^{11}$ predicted a median digital recovery time of $<240$ seconds in healthy males, when $6{ }^{\circ} \mathrm{C}$ was set as the recovery threshold. In our population

Table 6 Multivariate linear regression of test finger temperature $\left({ }^{\circ} \mathrm{C}\right)$ after rewarming and an additional $10 \mathrm{~min}$ recovery period at follow up test

\begin{tabular}{llc}
\hline Variable description & $\begin{array}{l}\text { Coefficient } \\
(\mathbf{9 5 \%} \mathrm{Cl})\end{array}$ & $\mathrm{Pr}>|\mathbf{t}|$ \\
\hline $\begin{array}{l}\text { Test finger temp ( } \mathrm{C} \text { C) after } \\
\text { rewarming and an additional }\end{array}$ & $0.237 \pm 0.143$ & 0.0014 \\
$\begin{array}{l}10 \text { min recovery period at } \\
\text { initial test }\end{array}$ & & \\
$\begin{array}{l}\text { Age at second test } \\
\text { Interval (mth) between last }\end{array}$ & $-0.0205 \pm 0.058$ & 0.4902 \\
$\begin{array}{l}\text { exposure and second test } \\
\text { Years exposed on job }\end{array}$ & $0.0468 \pm 0.0697$ & 0.1901 \\
$\begin{array}{l}\text { Smoking status at second test } \\
\text { Baseline finger temp ( } \mathrm{C} \text { C) }\end{array}$ & $0.399 \pm 0.0932$ & 0.4019 \\
at initial test & $-0.0927 \pm 0.190$ & 0.3410 \\
$\begin{array}{l}\left.\text { Baseline finger temp ( }{ }^{\circ} \mathrm{C}\right) \\
\text { at follow up test }\end{array}$ & $0.8305 \pm 0.162$ & $<0.0001$ \\
$\begin{array}{l}\text { FSBP\% at initial test } \\
\text { FSBP\% at follow up test }\end{array}$ & $-0.00220 \pm 0.0133$ & 0.7458 \\
$\begin{array}{l}\text { Stockholm Workshop Scale } \\
\text { symptom stage at second test }\end{array}$ & $0.0248 \pm 0.0152$ & 0.0016 \\
\hline
\end{tabular}

Estimates of regression coefficients (standard errors) are shown. 
median recovery was less than half as great at 600 seconds. However, their technique differed, involving gloving and circumferential sensor placement. An even more accelerated rewarming rate $\left(\sim 5.0^{\circ} \mathrm{C} / \mathrm{min}\right)$ was described for control subjects cooled with a dual inlet cuff, similar to that used in these trials. ${ }^{13}$

Aneklo-Noblin and colleagues ${ }^{13}$ made similar cross sectional observations that delayed skin temperature recovery was far more common than abnormal finger systolic blood pressure in symptomatic subjects. They posited that for many VWF cases, injuries were restricted to skin and its blood vessels, rather than to digital arteries. A defect in autonomic modulation of the feed capillary bed in VWF has been suggested. ${ }^{14}$

The measurement of vascular flux by laser Doppler, optically set at different skin depths, suggests significant differences in finger blood flow between deep and superficial vessels, with FST more closely related to the latter. ${ }^{15}$ There is also evidence that finger blood flow measured by laser Doppler diminishes progressively with decreasing external temperature. ${ }^{16}$ Moreover, in a study that has several parallels to this work, Allen and colleagues ${ }^{17}$ showed that $10.1 \%$ of a population of vibration exposed riveters were able to maintain arterial perfusion during cold challenge, measured by laser Doppler, but had prolonged reductions in capillary flux after rewarming. Symptoms were not, however, prominent, even when FSBP was abnormal.

The lack of concordance between skin temperature and symptoms has been described. The monitoring of digital skin temperature in VWF patients, after cold challenge, has been extensively reviewed..$^{11}{ }^{18}$ Because there is such variety in temperature recovery measurement techniques, comparisons are difficult; of more significance, there has been little obvious relation between test results and reported symptoms. A recent cross sectional evaluation of more than 20000 subjects in the UK employed cold provocation testing using skin temperature as the principal test outcome. ${ }^{19}$ There was no correspondence with symptoms of vibration related vasospastic disease assessed by the Stockholm Workshop Scale. ${ }^{9}$ The availability of longitudinal data in the current study offers a perspective on FST maintenance and recovery that has not been available in other comparable studies.

In general, a more extreme vasoconstrictive response implies a slow pattern of skin temperature recovery. Exaggerated vasoconstriction can inhibit the normal periodic increase and decrease in skin temperature during cold exposure. ${ }^{20}$ While pathological vasoconstrictor mechanisms may account for some of the delay in FST recovery, impairments in vasodilatation may also be important. There is substantial evidence that VWF is a consequence of impaired vasoregulatory function in the hand. ${ }^{21}$ The circulation in the fingers involves cholinergic, adrenergic, and serotonergic receptors with interplay between vasoregulatory systems. ${ }^{22}$ Pharmacologically demonstrable defects occur at the alpha 1-alpha 2 axis $^{23}$ and effect EDRF (endothelium derived relaxation factor) controlled vascular tone. ${ }^{24}$ There are anatomic and vasoregulatory correlates. Capillary regulation occurs at the epidermal ridge, $2 \mathrm{~mm}$ below the skin surface, while arterial structures are deeper (the digit has very limited collateralisation). Capillary flow is primarily mediated by neurotransmitter vasoregulation, in contrast to larger arteries that are under myogenic (arterial smooth muscle) regulation. Arneklo-Nobin and colleagues ${ }^{13}$ observed that smokers with symptomatic vibration induced Raynaud's and comparably exposed and symptomatic non-smokers both experienced a significant drop in FSBP\% on cold challenge. The mechanism differed: smokers had both an arterial vasoconstrictor and peripheral cutaneous response; nonsmokers only had reduction in skin circulation. Cherniack and colleagues ${ }^{5}$ made a similar observation, and hypothesised that the prolonged relative morbidity of smokers with VWF after exposure was related to arterial vasoconstriction. Based on these observations and results from the current study, it seems possible that impaired cutaneous circulation provides a general explanation for unimproved FST in the setting of improvement in FSBP. The mechanisms are not understood, but may reflect receptor effects at the level of arteriovenous anastamoses. ${ }^{12}$ Pacinian corpuscles, which are extremely responsive to vibration, are commonly located at these sites. A combination of impaired endothelium mediated vasodilatation and impaired local vasoconstriction accords with results presented in this study.

Vasoconstrictor effects on delayed skin temperature recovery are, over time, potentially less important as cold hands become more directly related to impairments in vasodilatation. Allen and colleagues ${ }^{17}$ found anamnestic information to be rather unreliable. As acute dramatic vasoconstrictive episodes lessen, individuals may become more attuned to cold hands and chronic symptoms. This does not satisfactorily explain why recovery temperature was cooler in the initial test for stage I-II subjects or why symptom associations are poor. It does suggest that symptoms may coincide with competing physical events.

The results illustrate the problems posed by assuming potential associations between finger skin temperature, cold provocation, and symptoms in VWF. Under some test conditions and for selected test protocols, the recovery pattern of skin temperatures may be a tool for disease differentiation. ${ }^{25}$ However, prolonged symptom severity in the setting of improving vasospasm and diminished temperature recovery, as reported here, while potentially specific to the population and experimental technique, makes broad application conditional.

\section{CONCLUSION}

This study suggests that a sizeable fraction of subjects with exposure to vibratory tools, who report prolonged cold related vascular symptoms, have delayed recovery in finger skin temperature following cold challenge. This pattern is evident in subjects who remain symptomatic, several years after removal from exposure, despite significant improvement in cold challenged FSBP. Unlike finger systolic blood pressure, neither symptom stage nor skin temperature substantially change on follow up, although the association between symptom stage and skin temperature is weak. Stockholm Workshop vascular symptom stage does not seem to predict skin temperature or longitudinal improvement in FSBP\%.

\section{ACKNOWLEDGEMENTS}

We wish to acknowledge the National Institute for Occupational Safety and Health for its support of vibration related research.

\section{Authors' affiliations \\ M Cherniack, A Brammer, J Meyer, T Morse, D Peterson, R Fu, University of Connecticut Health Center, Farmington, CT, USA}

\section{REFERENCES}

1 Nielsen SL. Raynaud's phenomenon and finger systolic blood pressure during cooling. Scand J Clin Lab Invest 1980;38:765-70.

2 Bovenzi M. Digital arterial responsiveness to cold in healthy men, vibration white finger and primary Raynaud's phenomenon. Scand J Work Environ Health 1993;19:271-6.

3 Harada N, Yoshimura M, Laskar MS. A mini-review of studies conducted in Japan using finger-skin temperature during cold-stress tests for the diagnosis of hand-arm vibration syndrome. Int Arch Environ Health 1999;72:330-4.

4 Pelmear PL, Roos J, Leong D, et al. Cold provocation from a 1985 survey of hard-rock miners in Ontario. Scand J Work Environ Health 1987;13:334-47.

5 Cherniack M, Clive J, Seidner A. Vibration exposure, smoking, and vascular dysfunction. Occup Environ Med 2000;57:341-4. 
6 Olsen N. Diagnostic tests in Raynaud's phenomena in workers exposed to vibration: a comparative study. Br J Ind Med 1988;45:426-30.

7 Peterson R, Andersen M, Mikkelsen S, et al. Prognosis of vibration induced white finger: a follow up study. Occup Environ Med 1995:52:1 10-15.

8 Futatsuka M, Ueno T, Sakurai T. Cohort study of vibration-induced white finger among Japanese forest workers over 30 years. Int Arch Environ Health 1989;61:503-6.

9 Gemne G, Pyykko I, Taylor W, et al. The Stockholm workshop scale for the classification of cold-induced Raynaud's phenomenon in the hand-arm vibration syndrome (revision of the Taylor-Pelmear Scale). Scand J Work Environ Health 1987; 13:275-58.

10 Nielsen SL, Lassen NA. Measurement of digital blood pressure after local cooling. J Appl Physiol 1977;43:907-10.

11 Lindsell CJ, Griffin MJ. Interpretation of the finger skin temperature response to cold provocation. Int Arch Environ Health 2001;74:325-35

12 Virokanas $\mathbf{H}$, Rintamaki $\mathrm{H}$. Finger blood pressure and rewarming rate for screening and diagnosis of Raynaud's phenomenon in workers exposed to vibration. Br J Ind Med 1991;48:480-4.

13 Arneklo-Nobin B, Johansen K, Sjoberg T. The objective diagnosis of vibration-induced vascular injury. Scand J Work Environ Health 1987;13:337-42.

14 Gemne G, Pyykko I, Starck J, et al. Circulatory reaction to heat and cold in vibration-induced white finger with and without sympathetic blockade-an experimental study. Scand J Work Environ Health 1986;12:371-7.

15 Mirbod SM, Yoshida H, Jamali M, et al. Finger skin temperature and laserDoppler finger blood flow in subjects exposed to hand-arm vibration. Ind Health 1998;36:171-8.
16 Allen JA, Doherty CC, McGrann S Objective testing for vasospasm in the hand-arm vibration syndrome. Br J Ind Med 1992;49:688-93.

17 Allen JA, McGrann S, McKenna KM. Use of questionnaire screening for vibration white finger in a high-risk industrial population. Int Arch Occup Environ Health 2002;75:37-42.

18 Harada N. Cold-stress tests involving finger skin temperature measurement for evaluation of vascular disorders in hand-arm vibration syndrome: review of the literature. Int Arch Environ Health $2001 ; 75: 14-19$.

19 Lawson IJ, McGeoch KL, Burke F, et al. cold provocation testing in a large volume of medico-legal compensation claims for HAVS. 9th International Conference on Hand-Arm Vibration. 5-8 June 2001, Nancy, France.

20 Spurr GB, Hutt PT, Horvath SM. The effects of age on finger temperature responses to local cooling. Am Heart J 1955;50:551-5.

21 Olsen N. Hyperreactivity of the central sympathetic nervous system in vibration-induced white finger. Kurume Jed J 1990;37:S109-16.

22 Lindblad KL, EkenvallL. Alpha2-adrenoreceptor inhibition in patients with vibration white finger. Kuruma Med J 1990;37:S95-9.

23 Vanhoutte PP, Cooke JP, Lindblad LE, et al. Modulation of postjunctional alpha-adrenergic responsiveness by local changes in temperature. Clin Sci 1985;68:121-35.

24 Gemne G. Pathophysiology and pathogenesis of disorders in workers using hand-held vibrating tools. In: Pelmear, Taylor, Wasserman, eds. Hand-arm vibration. New York: Van Nostrand Reinhold, 1992:41-76.

25 Coughlin PA, Chetter IC, Kent PJ, et al. The analysis of sensitivity, specificity, positive predictive value and negative predictive value of cold provocation thermography in the objective diagnosis of the hand-arm vibration syndrome. Occup Med 2001;51:75-80.

\section{$\mathrm{ECHO}$}

\section{Secondhand smoke exposure remains a risk in Massachusetts restaurants despite} widespread adoption of smoking regulations

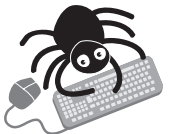

Please visit the Occupational and

Environmental Medicine website [www. occenvmed. com] for a link to the full text of this article. survey of restaurant smoking regulations in the 351 towns and cities in Massachusetts found that $82 \%$ of adults and $82 \%$ of youths are not guaranteed protection from - secondhand smoke in restaurants in their town of residence. The same proportion of restaurant workers and $87 \%$ of bar workers are similarly not protected.

The survey looked at the smoking regulations from each town relating to customers and employees and classified them into eight categories according to whether there were no restrictions in place, limited restrictions (such as smoking only in separate ventilated areas or bar areas) or a complete ban on smoking. The proportion of the population in each town covered by the regulations was estimated from census data. The number of bar and restaurant staff was estimated to be proportional to the town population.

Although 225 towns had adopted some type of smoking regulation only 60 (covering $17.7 \%$ of the population) completely banned smoking in restaurants. The remainder restricted smoking in some way-174 of these to bar areas or separately ventilated areas, although 35 of these still allowed for variation to the regulations.

This study shows that classifying some restaurants and bars as "smoke free" may be misleading, and argues that there may be customers, and especially restaurant and bar staff, who are still exposed to cigarette smoke. It also calls for public health workers to tighten up their implementation of smoking regulations.

A Tobacco Control 2003;12:221-226. 